\title{
ASPECTOS DO TEMPO EM \\ QUATRO-OLHOS, DE RENATO POMPEU
}

http://dx.doi.org/10.11606/issn.2237-1184.v0i29p166-180

\author{
Carlos Moacir Vedovato Junior \\ Universidade de São Paulo (USP) \\ Ivone Daré Rabello \\ Universidade de São Paulo (USP)
}

\section{RESUMO}

O objetivo deste artigo é analisar aspectos do tempo no romance Quatro-Olhos (1976), de Renato Pompeu. Ao longo da trama, a personagem central busca rememorar sua história e seus projetos em oposição ao presente em que está inscrito, no momento em que está internado em um hospital psiquiátrico. Na tentativa delirante de rememoração, pode-se entrever o confronto entre um tempo pretérito em que havia horizontes de superação para os problemas da formação nacional brasileira e um tempo presente, da enunciação, em que as ações parecem não ter mais sentido.

\section{ABSTRACT}

The main objective of this article is to analyze aspects of the temporality of the novel Quatro-Olhos (1976), from Renato Pompeu. Throughout the plot, the main character tries to remember his story and his life projects as an opposition to the present time in which he finds himself, in a psychiatric hospital. In his delusional attempt of remembrance one can glimpse the conflict between a previous time, in which the problems of the brazilian national formation seemed to have overcoming horizons, and the time in the present, from where he enunciates, in which the actions do not seem to make sense anymore.

\section{PALAVRAS-CHAVE:}

Romance brasileiro; Quatro-Olhos; ditadura militar; Renato Pompeu.

\section{KEYWORDS}

Brazilian novel; Quatro-Olhos; military dictatorship; Renato Pompeu. 
O romance Quatro-Olhos ${ }^{1}$, de Renato Pompeu, foi publicado em 1976 no início da chamada Abertura Política do regime militar brasileiro. Àquela altura, à medida que se consolidava a Indústria Cultural no país", modernizava-se o mercado editorial, dando início ao "boom literário". Com a diminuição da censura, entre as novidades que ocupavam as estantes de obras nacionais, estavam publicações em prosa que colocavam em cena episódios ocorridos ao longo da ditadura que não puderam ser publicados nos jornais ${ }^{3}$ e os depoimentos de ex-militantes da luta armada. ${ }^{4}$ A esse conjunto de intenção mais acentuadamente mimética, parte da crítica ${ }^{5}$ opôs uma série de obras em que se sobressaía a experimentação artística. Primando pela inventividade enquanto valor artístico, a crítica que se empenhou em compreender a literatura produzida entre os anos sessenta e setenta foi unânime em localizar Quatro-Olhos no campo da inovação linguística.

Digamos, então, que o juízo que se funda no critério de inventividade utilizado por parcela da crítica teve seu lugar na história de nosso ensaísmo: tratava-se naquele momento de mapear, ainda que de maneira genérica - talvez única forma possível para panoramas - , a prosa produzida no país nos anos de ditadura militar; entretanto, passados os anos, é preciso investigar de maneira mais detida parte dessas obras. No caso de Quatro-Olhos, um caminho para isso é investigar a qual experiência histórica corresponde a inventividade de sua forma - tão celebrada pela crítica - , encaminhando a leitura menos pelo esteticismo vigente naqueles anos que pela compreensão dos significados vinculados a essa forma.

\section{2.}

\footnotetext{
1 POMPEU, R. Quatro-Olhos. SP: Alfa-ômega, 1976.

2 ORTIZ, R., A moderna tradição brasileira. SP: Brasiliense, 1995.

${ }^{3}$ ARRIGUCCI JR., D.; VOGT, C.; AGUIAR, F.; WISNIK, L. T.; LAFETA, J. L. “Jornal, Realismo, Alegoria" (Romance Brasileiro Recente). Remate de Males, n. 1, 1979, pp. 11-50.

${ }_{4}^{4}$ As obras alcançavam recordes de vendas, como atesta a vigésima quarta edição de $O$ que é isso, companheiro?, de Fernando Gabeira, dois anos após seu lançamento. (RJ: Editora Codecri, 1981, $24^{\mathrm{a}}$ edição).

${ }^{5}$ Ver GONÇALVES, M. A.; HOLLANDA, H. B. de. "Política e literatura: a ficção da realidade brasileira". In: Anos 70 literatura. RJ: Europa empresa gráfica, 1979-1980; SUSSEKIND, F., Literatura e vida literária, polêmicas, diários \& retratos. RJ: Zahar, 1985.
} 
Dividido em três partes - "Dentro", "Fora" e De volta" - QuatroOlhos tem como um de seus núcleos temáticos a tentativa da personagem principal de reescrever um manuscrito perdido que supostamente elaborara no passado. Até o último momento da primeira parte não sabemos como ele se perdera - mas é o próprio narrador quem esclarece, então, que ele fora levado pela polícia política do regime militar quando a repressão buscava pela sua esposa; não a tendo encontrado, levaram-no e a seus escritos no lugar dela. Sobre o manuscrito, diz logo no primeiro parágrafo do romance:

Mais ou menos dos dezesseis aos vinte e nove anos passei no mínimo três a quatro horas todos os dias, com exceção de um ou outro sábado e de certa segunda-feira, escrevendo não me lembro bem se um romance ou um livro de crônicas. Recordo com perfeição, porém, tratar-se de obra admirável, a pôr a nu de modo confortavelmente melancólico a condição humana universal e eterna, particularizada com emoção discreta nas dimensões nacionais e de momento. ${ }^{6}$

De início a leitura provoca estranhamento. O personagem, que narra a primeira parte, diz ter escrito algo de valor elevado, embora não se lembre exatamente do que se tratava. No estilo de quem tomou contato com as belas letras, que faz lembrar o primeiro parágrafo das Memórias Póstumas de Brás Cubas7, seja pelo jogo dual dos termos (dezesseis aos vinte e nove anos; um ou outro sábado/ e de certa segunda-feira; um romance/ ou um livro de crônicas; universal e eterna; dimensões nacionais e de momento), seja pela exaltação do livro que produzira ("recordo [...] tratar-se de obra admirável"), o narrador pode provocar riso. A citação cifrada, somada às de outras grandes obras que se espalham ao longo da primeira parte (São Bernardo, Macunaíma, A Rosa do povo) - que, a um tempo, aproximam o protagonista da tradição literária brasileira e fazem ver seu conhecimento letrado - e a condição de quem não se lembra do que escreveu, se transformam em certo mal-estar para o leitor, quando se sabe, na segunda parte, o que apenas se sugeria na primeira: a personagem está internada em um hospital psiquiátrico, após ter sido presa pela polícia política da ditadura. $\mathrm{Na}$ instituição, recebe o apelido que dá título ao romance, Quatro-Olhos ao longo de toda a trama não sabemos seu verdadeiro nome.

\footnotetext{
${ }^{6}$ POMPEU, R. Op. cit., p. 15.

${ }^{7}$ Ver a análise de Roberto Schwarz nos capítulos "Observações iniciais" e "Um princípio formal" In: Idem. Um mestre na periferia do capitalismo: Machado de Assis. SP: Ed. 34, 2012.
} 
Evidencia-se, então, na segunda parte de Quatro-Olhos, que a primeira, "Dentro" (o conjunto de fragmentos), foi escrito dentro do hospital, quando o protagonista busca rememorar os acontecimentos da vida no passado (compostos por sua juventude, quando desejava tornarse latinista, sua vida universitária, seu trabalho como gerente de um banco e seu casamento), reescrever o livro perdido; além disso, narra a busca delirante do manuscrito perdido pela cidade de São Paulo que, na cronologia da fábula, ocorreu entre a prisão e a internação.

Em termos gerais, mais do que lembrar, trata-se de uma tentativa de rememorar, a que se somam saltos abruptos em um mesmo parágrafo e a mistura constante dos assuntos, bem como a alteração de tonalidades. Parcialmente isso se explica quando, na segunda parte, se explicita que a escrita da primeira está submetida à lógica delirante de quem está internado em um hospital psiquiátrico, confundindo vida pretérita, ficção e alucinação. $O$ narrador se inscreve em um presente enunciativo em que "parece não haver muito para fazer além de lembrar". 8 No confronto entre esses dois tempos - pretérito e presente enunciativo - parece residir uma das chaves de compreensão do romance.

3.

Tomemos, para a análise de alguns aspectos da temporalidade em Quatro-Olhos, a reflexão desenvolvida por Éugène Minkowski ${ }^{9}$, na primeira metade do século $\mathrm{XX}$ sobre o tempo vivido, após a guerra de trincheiras. ${ }^{10} \mathrm{Em}$ Le temps vécu, tratava-se, no que nos interessa neste estudo, de pensar como estava contida na vivência do presente o próprio tempo futuro, à luz do pensamento de Bergson. Assim, partindo do conceito de duração, estabelecia, a certa altura da obra, duas categorias: a atividade e a expectativa - opostas e complementares para a vivência do indivíduo no tempo.

A atividade seria uma "manifestação global do ser vivente"11, um fenômeno vital essencial - "único meio de avançar realmente na vida"12 - que direciona a ação dos indivíduos para o futuro. Nesses termos, enquanto direção das ações, enquanto movimento que faz avançar no tempo, é na atividade que se vive qualitativamente o tempo, a própria duração - o que pressupõe o futuro como horizonte. Em outros termos, na duração, na experiência qualitativa do tempo, está contido o olhar em direção ao futuro, que, por sua vez, nutre a atividade.

\footnotetext{
8 POMPEU, R. Op. cit., p. 40.

${ }^{9}$ Devemos a sugestão ao professor Dr. Anderson Gonçalves.

${ }^{10}$ MINKOWSKI, E. Le temps vécu, Paris, Quadrige, 2013.

${ }^{11}$ Idem, ibidem, p. 75.

${ }^{12} I d ., i b .$, p. 76.
} 
Na expectativa, em oposição à atividade, não há duração, mas sucessão. Não há experiência qualitativa do tempo, na medida em que não há atividade - o que promove a qualidade da vivência. Também em oposição à primeira categoria, em vez de se avançar em direção ao futuro, é o futuro que avança na direção do indivíduo, "em toda sua impetuosidade" 13 tornando-se presente. Como o futuro se torna presente, não há propriamente um horizonte.

As duas categorias, atividade e expectativa, caracterizariam a relação dos indivíduos com o tempo vivido. Interpretando Minkowski, poderíamos dizer que a sucessão das ações se dá fora do indivíduo, bem como a duração se dá dentro dele.

\section{4.}

Valendo-nos, para a análise, das categorias de Minkowski, parece haver em Quatro-Olhos, na primeira e segunda partes, um confronto entre o que poderíamos chamar de tempo da atividade e tempo da expectativa, na medida em que ambas ocorrem simultaneamente.

"Fora" está dividida em quatro capítulos, e é a parte do romance em que se deixa ver a organização da vida no hospital psiquiátrico. $O$ primeiro, que nos interessa aqui, é a narração de um dia - do amanhecer ao anoitecer - na instituição. O capítulo, agora em terceira pessoa, se inicia e se encerra com a busca de uma das personagens por uma moça, Bastiana. Os outros internados, por não compreenderem que se trata de uma busca, apelidam a personagem com o nome da moça por quem procura. Essa moldura da narrativa por uma ação que ocorre todos os dias garante um aspecto cíclico à vida no hospital.

Além das buscas por Bastiana, os outros pacientes protagonizam pequenas ações cujo valor parece se encerrar em si, já que não apresentam consequências para o andamento da trama. O que coordena e organiza essas ações é a organização temporal do próprio hospital: todas estão submetidas à sucessão de eventos da própria instituição. Assim, acompanhamos café da manhã, fila de remédios, almoço, lanche da tarde, fila de cigarros, jantar e uma espécie de show de calouros promovido pelo hospital. Entre os acontecimentos previsíveis do cotidiano hospitalar ocorrem ações protagonizadas pelas personagens em delírio: um acredita ser o Messias, outro vê insetos em todos os lugares, outro ainda esmaga a própria cabeça com uma bola de ferro.

Entre os internados, há ainda um grupo que encena uma espécie de paródia da resistência à ditadura, os conspiradores:

${ }^{13} I d .$, ib., p. 81. 
Do outro lado das paredes, no pátio, os conspiradores contavam o trunfo do dia, mas eles mesmo estavam divididos. Uma ala queria atribuir à administração apenas as falhas decorrentes do seu modo de lidar com as coisas; outro grupo porém queria lançar a culpa na direção por tudo que acontecia. Por exemplo, naquela manhã alguns pacientes tinham voltado da saída bêbados e alguns conspiradores queriam atirar isso no rosto da administração, por não ter tratado direito os doentes, enquanto grande parte dos outros conspiradores viam nessa manobra um meio de desmoralizar o movimento e começavam a duvidar dos companheiros que defendiam essa linha de ataque. Para eles, voltar embriagado de uma saída era simplesmente um direito do paciente e isso é que devia ser defendido junto à direção do hospital, não culpá-la por um ato sobre o qual ela não tinha o menor domínio. O cabeça dos conspiradores, partidário dessa última posição, já se convencia de que era necessário um expurgo, sob pena de os mais radicais acabarem fazendo o jogo da direção.

Não era, no entanto, uma reunião organizada, a maioria nem sabia que se tratava de um encontro de conspiradores, que só adquiria substância na cabeça do chefe, a hidra farejada por Aleijado. Era simplesmente um grupo de pessoas conversando no pátio, só alguns com a ideia de que aquilo tinha um objetivo. Isso vinha complicar a missão do líder, já agora certo de que era inevitável o expurgo. ${ }^{14}$

Os participantes da conspiração se reúnem às escondidas pensando em possibilidades de enfrentamento das regras do hospital, sendo procurados por colaboradores da instituição, como o interno Aleijado. Note-se a especificidade do vocabulário particular dessas passagens: "companheiros", "expurgo", "desmoralização do movimento", "linha de ataque"; palavras que compunham o discurso dos grupos à esquerda de resistência à ditadura. No conjunto, essa parcela da esquerda, que ganha figuração na segunda parte do romance, é colocada lado a lado com outros pacientes enlouquecidos. Em palavras mais diretas, suas ações, sob o ângulo do romance, são tão relevantes quanto as do sujeito que acredita ser o Messias. São, então, como as dos outros internados, ações sem consecutividade. As ações sem consequências dão ao presente, no hospital, um aspecto próximo ao que Minkowski chamou de expectativa. Mesmo quando há alguma ação que visa ao futuro (como o trecho citado), o presente se esvazia, na medida em que as ações se tornam irrelevantes para o andamento da trama. No conjunto as ações se organizam pela repetição:

${ }^{14}$ POMPEU, R. Op. cit., p. 156. 
os conspiradores estão sempre conspirando, outro internado, sempre vendo insetos, e outro, ainda, sempre agindo como se fosse o Messias.

Mas a esse tempo da expectativa opõe-se a tentativa de recuperar o passado empreendida por Quatro-Olhos, que é, por sua vez, sempre nos termos de Minkowski, atividade. Isso porque ao tempo esvaziado do presente, opõe-se o tempo da atividade de rememorar. Vejamos, então, a qual pretérito corresponde aquilo que o protagonista tenta lembrar.

\section{5.}

No conjunto de fragmentos a que temos acesso em "Dentro", como dissemos, misturam-se a rememoração delirante da vida passada, a suposta busca pelo manuscrito e a retomada daquilo que estava escrito na obra perdida. À vida pretérita correspondem os momentos de juventude, quando, diferenciado dos seus pares na escola pública por suas condições de classe, o protagonista podia dedicar-se à aspiração intelectual de tornarse latinista; também se retoma sua entrada na universidade e a aproximação do movimento estudantil, quando conhece sua esposa, liderança política, que o escolhe por ver nele alguém do "povo", já que trabalhava e estudava ao mesmo tempo. À saída da universidade se sucede o ingresso no mercado de trabalho. Após ter cursado economia e administração, o protagonista trabalha, por indicação, como gerente de um banco, onde instala computadores "para o desespero dos clientes".

Somados aos aspectos que poderíamos chamar mais especificamente de autobiográficos, a rememoração do passado permite entrever os momentos históricos em que se inscrevem esses aspectos. A referência ao movimento estudantil e à sua relação com o "povo" remetem-nos aos anos de 1960. Corroborando isso, na trajetória rememorada da personagem, quando, a certa altura da primeira parte, o protagonista rememora seu primeiro voto, lemos:

O nordestino do voto em branco ou nulo tinha o rosto chupado como de varíola e falava sem parar na nouvellevague francesa no cinema; insistia em que a literatura se dirigia ao homem só sentado a uma poltrona na sala burguesa com iluminação difusa e o soalho pintado de branco e preto - à parede haveria papéis com anjos tocando harpas em fileiras uniformes, tudo meio sobre o rosa e o azul, com folhagens de um verde esmaecido. Assim estava decretada a falência da literatura, o que valia era o cinema, dirigido à massa e incentivador do diálogo entre os espectadores e por isso mesmo o mau filme era válido, por gerar a recusa, e a recusa como aceitação, era afinal uma atitude e justamente o que era necessário era fazer a massa 
assumir atitudes. Talvez nesse sentido o mau filme fosse superior ao bom, que originaria apenas uma aprovação passiva. Portanto, tratava-se de fazer maus filmes, fomentando a discussão e a vaia. Em breve, desse modo, a massa estaria em estado de efervescência, preparada para a ação e a um passo da ação. ${ }^{15}$

O episódio diz respeito às eleições que levariam ao poder Jânio Quadros em 1961 - como se nota em trecho imediatamente anterior. Mais que a datação política em sentido estrito, porém, interessam-nos as reflexões do narrador sobre a personagem a que ele remete. A descrição ridiculariza a personagem e o que ela dizia. $O$ narrador caracteriza o nordestino com um "rosto chupado", sem distinguir se ele defendia o voto nulo ou branco - dando a entender que, para ele, Quatro-Olhos, essa preocupação não tinha importância; repõe parte do argumento com uma sequência de orações coordenadas pela conjunção " $\mathrm{e}$ ", fundamentando, em termos rítmicos, a ideia de que o nordestino falava sem parar; além disso, de maneira caricata, pelo uso do indireto, atribui a esse homem a afirmação de que ele decretara o fim da literatura e a ideia de que o mau filme seria melhor que o bom por suas condições de provocar as ações do povo. Pelo ângulo desse narrador, está ridicularizada nessa passagem uma espécie de súmula de proposições da arte avançada do período. $\mathrm{O}$ trecho poderia, assim, ser lido como uma caricatura mal-intencionada de um Glauber Rocha, por exemplo.

E em outro trecho:

$\mathrm{Na}$ faculdade eu votava com os mais extremistas e me oferecia para pequenas tarefas, tais como dormir na sede do grêmio durante as ocupações da escola na campanha para conseguir que a direção universitária fosse composta de um terço dos alunos. Então eu dormia sobre o chão num saco de dormir, tomando muita pinga. Mas confesso que não me interessavam as discussões sobre alta política nas assembleias; tudo de que eu queria saber eram as propostas imediatas e eu apoiava sem pensar muito o que me parecia mais avançado, greves e ocupações. ${ }^{16}$

Agora o trecho parece referir-se à chamada "greve do 1/3"17 de 1962. Não se trata, como na passagem anterior, da ridicularização dos

\footnotetext{
${ }^{15}$ Idem, ibidem, p. 121.

${ }^{16} I d ., i b .$, p. 98.

${ }_{17}$ Segundo Rodrigo Patto Sá Motta, a chamada "greve do 1/3", desencadeada na Universidade de São Paulo em 1962, além de exigir a participação estudantil nessa proporção, dava mostras dos interesses dos estudantes, para os quais "a universidade deveria ter estrutura mais moderna e ágil, capaz de produzir conhecimento útil ao desenvolvimento, mas deveria colocar-se também
} 
posicionamentos políticos de outros militantes, mas de um relato algo caricato da participação da própria personagem no movimento estudantil. Ao passo que o trecho dá testemunho da participação pouco envolvida da personagem, diz também sobre uma espécie de autoconsciência da condição de "massa de manobra", o que constitui, aliás, uma leitura corrente e sintomática à época.Ambos os trechos, e poderíamos apontar outros, dão notícias de episódios históricos em que estava na ordem do dia a possibilidade ou a crença de que se poderiam superar os problemas históricos ligados à formação brasileira e a posição desse protagonista diante dessas possibilidades.

No que diz respeito aos episódios históricos, sabemos - já que o primeiro voto aos dezessete anos do protagonista se dá nas eleições de Jânio Quadros em 1961 -, que a personagem nasceu por volta de 1944: momento decisivo do processo de modernização do país que se inicia no primeiro governo de Getúlio Vargas, mais especificamente a partir do Estado Novo (1937-1945). Pensando o período, Celso Furtado argumenta que, com o passar do tempo, na medida em que consolidava as diferenças sociais características de nossa formação, cujo maior emblema sempre foi o latifúndio, o processo modernizador deixava ver seu caráter antipopular, levando parte da população, sobretudo a juventude universitária, à defesa de projetos que caracterizariam o que o economista chamou de tempos de "pré-revolução". 18 No romance que estamos analisando, vemos, pela própria biografia de Quatro-Olhos, a ascensão das classes médias urbanas, bem como o engajamento da juventude universitária e a renovação da vida artística nacional a partir de diversos projetos estético-políticos motivada pela possibilidade de uma alteração radical do quadro em que se inseria. Tudo isso marcas de um percurso que se estende do Estado Novo aos anos imediatamente anteriores ao golpe que daria início à Ditadura em 1964, o que revelaria o verdadeiro fundamento da modernização, à medida que enterraria os projetos de mudança daqueles anos de pré-revolução. No romance, ao ridicularizar os agentes desse momento, Quatro-Olhos põe em causa sua significação.

Mas, ao mesmo tempo que a personagem ridiculariza aqueles projetos políticos, também em sua rememoração o que se pode entrever é um projeto. Quando, a certa altura dos fragmentos iniciais do romance, enuncia o tema do livro perdido diz tratar-se de "uma flor velha; já perdida a cor e com uma sombra de perfume, a heroína do livro". ${ }^{19}$ Diz também que quando compunha o livro "a roseira já prefigurava uma ameaça a

ao lado das causas sociais e servir de vanguarda às transformações socialistas". In: Idem. As universidades e o regime militar: cultura política brasileira e modernização autoritária. RJ: Zahar, 2014.

${ }^{18}$ FURTADO, C. A pré-revolução brasileira. RJ: Fundo de cultura, 1962.

${ }^{19}$ Idem, ibidem, p. 138. 
alguns. Mas isso só entendi mais tarde, quando já tinha deixado o livro" 20 - numa possível referência indireta aos "anos de chumbo", quando o protagonista foi preso e levado ao hospital. A imagem da rosa não é novidade em nossa tradição literária: símbolo socialista ao longo do século XX, está no título de um dos livros mais empenhados de um de nossos maiores líricos - A Rosa do povo, de Carlos Drummond de Andrade. Numa referência ao livro do poeta mineiro, diz o protagonista sobre o tema das rosas no manuscrito: "Dediquei páginas à flor estéril a brotar num interstício de cimento" 21 , retomando célebre verso de "A flor e a náusea".

Ao acentuar em diversas passagens a importância da rosa em seu livro perdido, Quatro-Olhos deixa ver sua relação pessoal com os sonhos do passado: reescrever o manuscrito é também a recuperação de uma utopia - voltaremos a essa questão. Por ora basta dizer que a recuperação da utopia - inscrita entre aquelas que o próprio protagonista ridicularizava - por via da rememoração do passado funciona no romance como uma espécie de luta contra o presente esvaziado. Recuperar o passado na memória, mas também tentar reescrever o livro perdido, são maneiras de tentar trazer ao presente, ainda que subjetivamente, o tempo pretérito da atividade - que projetava o futuro - em oposição ao presente da expectativa em que o tempo se repete - e não passa.

\section{6.}

Note-se, então, que esse tempo pretérito, figurado no romance, ou a hora histórica que Celso Furtado chamou de "pré-revolução", foi o momento em que se concentraram todas as expectativas - em múltiplas faces à direita e à esquerda - geradas pelo complexo desenvolvimentista que se instalara no país desde o Estado Novo. Para parte da esquerda, sobretudo aquela ligada ao Partido Comunista Brasileiro, tratava-se de superar os entraves da formação nacional, cuja lógica se desenvolvia desde o século XIX sob a dualidade atrasado versus moderno. ${ }^{22}$ Acreditava-se no empenho de uma burguesia nacional progressista ${ }^{23}$ que, tomando seu lugar na história, contribuiria para a superação daqueles problemas. Fundados mais ou menos nessa lógica vinham também à cena a renovação das esferas da arte e da intelectualidade mais avançadas. Era o projeto do Centro Popular de Cultura (ligado ao PCB), a renovação do cinema brasileiro com o Cinema Novo, o novo teatro político, os programas de

\footnotetext{
${ }^{20} I d .$, ib., p. 115.

${ }^{21} I d .$, ib., p. 100.

${ }^{22}$ Para a discussão mais avançada sobre o problema e a própria superação do dualismo, ver: OLIVEIRA, F. de. "Crítica da razão dualista" in: Crítica da razão dualista; O ornitorrinco. SP: Boitempo, 2003.

${ }^{23}$ SCHWARZ, R. “Cultura e política, 1964 - 1969” in: O pai de família e outros estudos. SP: Paz e terra, 1992.
} 
alfabetização, o elogio da cultura popular etc. ${ }^{24}$ Numa sentença já bastante conhecida, "o país estava irreconhecivelmente inteligente". ${ }^{25}$ Novamente recuperando e adaptando as categorias de Éugène Minkowski, era o tempo da atividade, um tempo vivido qualitativamente com vistas ao futuro, tendo como ponto de fuga um projeto de nação um tanto menos desigual.

Mas a todo esse processo o golpe militar lançou um ponto final. É claro que a ditadura que o segue não pode ser vista como um conjunto homogêneo, já que havia uma série de projetos diversos, seja entre o alto escalão da administração militar, seja entre a parcela da burguesia nacional que deu sustentação ao regime; entretanto, há um conjunto de consequências, que se iniciam já com o golpe, que lhe garantem um sentido. Paulo Arantes, parafraseando Caio Prado Junior, se pergunta se o "sentido da ditadura" não seria o processo em que "industrializamo-nos para nos reprimarizar reciclados agora na função de primárioexportadores de ativos financeiros de alta rentabilidade, ao lado da monocultura extensiva, da mineração, das commodities energéticas" ${ }^{26}$ Em outros termos, o processo modernizador nutria-se do atraso (a monocultura extensiva, seu maior símbolo), enquanto o antigo se consolidava no novo ("industrializamo-nos para nos reprimarizar"). Tudo isso fundado no regime truculento que, para além da tortura e assassinato dos presos políticos ligados à luta armada nos "anos de chumbo", dizimou aldeias indígenas, consolidou os massacres nas periferias urbanas, perseguiu trabalhadores, e, no conjunto, destruiu a possibilidade de uma alteração radical para o quadro nacional. 1964 inaugurou um "novo tempo brasileiro" 27, à medida que sua exceção tornou-se regra. O futuro, a modernização que se esperou ao longo do século, havia chegado e acertava os ponteiros da vida nacional com o novo tempo do mundo.

São esses dois tempos brasileiros que parecem estar formalizados em contraste nas duas primeiras partes de Quatro-Olhos. O passado que se tenta recuperar é o tempo da atividade, da ação guiada para a superação dos problemas nacionais. O presente da enunciação, por sua vez, é o tempo esvaziado da expectativa em que o futuro se presentifica, numa espécie de tempo que não passa para os derrotados, que ganham figuração no romance com os pacientes do hospital psiquiátrico. ${ }^{28}$

\footnotetext{
24 Para a discussão sobre as obras desse período, ver: XAVIER, I. Sertão mar, Glauber Rocha e a estética da fome. SP: Brasilense, 1983; COSTA, I. C. A hora do teatro épico no Brasil. SP: Expressão popular, 2016.

25 Idem, ibidem, p. 69.

26 ARANTES, P. “1964” in: O novo tempo do mundo. SP: Boitempo, 2014, p. 306.

${ }^{27}$ Idem, ibidem, p. 286.

${ }^{28}$ Não é excesso lembrar alguns aspectos de uma instituição psiquiátrica no país entre à altura da publicação do romance. Desde o início do século $\mathrm{XX}$, os antigos manicômios eram espaços em que eram despejados pobres, moradores de rua, militantes políticos etc. Um bom exemplo literário em que tais instituições ganham figuração é o Triste fim de Policarpo Quaresma (1915), de
} 
Ao presente esvaziado, então, Quatro-Olhos se opõe tentando recuperar algo do tempo da atividade: não os projetos políticos por ele ridicularizados, mas seu próprio projeto artístico e pessoal. Em "Dentro", temos acesso à tentativa de recompor esse passado, mas submetido à lógica daquilo que está "Fora" da personagem, ao tempo esvaziado, que submete a primeira parte à fragmentação, ao delírio, à mistura de assuntos.

7.

Na terceira parte, chamada "De volta", narrada também em terceira pessoa, acompanhamos a saída do protagonista do hospital psiquiátrico. Após uma tentativa de relacionamento fracassado com uma moça que estava saindo do Brasil ("No Brasil não dá pé, os americanos nunca vão deixar - ela disse" ${ }^{29}$ ) e de sua reinserção no mercado de trabalho, quando se torna "assistente de produção de filmes publicitários para a TV"30, Quatro-Olhos, agora sem as "linhas demarcatórias" 31 anteriores da vida emprego, esposa e livro - decide, em oposição ao "egoísmo da moça" 32 , diante da situação nacional, "escrever outra vez o livro". ${ }^{33}$ Assim se encerra Quatro-Olhos.

Quando já não está mais internado, o protagonista se propõe a retomar a ação central do romance: tentar reescrever o manuscrito perdido, encenando fora da instituição algo que caracterizava as ações no próprio hospital - a repetição. Agora, entretanto, a vontade política da ação se evidencia:

Quatro-Olhos ficou espantado com o egoísmo da moça, afinal ela estava adotando solução, a fuga do Brasil, à qual

\footnotetext{
Lima Barreto. Para um exemplo mais próximo do tempo de Quatro-Olhos, há o breve documentário de Helvécio Ratton, Em nome da razão, de 1979, quando está chegando ao país a luta antimanicomial, influenciada certamente pela História da Loucura (1961), de Michel Foucault, mas, sobretudo, pela influência do psiquiatra italiano Franco Basaglia, como atesta o recente Holocausto brasileiro, de Daniela Arbex, publicado em 2013 pela Geração Editorial. Note-se que o romance de Renato Pompeu dá figuração a uma instituição psiquiátrica que já não era mais o manicômio (os próprios internados no romance manifestam o medo do retorno à forma manicomial), mas ainda fazia parte do complexo psiquiátrico composto sobretudo por pobres e marginalizados lançados nessas instituições à própria sorte. Um último elemento para a compreensão da instituição que está em cena é que a referência de Renato Pompeu para a elaboração do romance foi sua própria experiência como paciente do Hospital Psiquiátrico do Juquery entre 1974 e 1975 após uma semana de tortura no início dos anos setenta, o que levou o jornalista a participar ativamente da luta antimanicomial - que, na época da internação de Pompeu, era ainda incipiente no país.

${ }^{29}$ POMPEU, R. Op. cit. p. 188.

${ }^{30} \mathrm{Idem}$, ibidem, ibidem.

${ }^{31} I d ., i b ., i b$.

${ }^{32} I d ., i b ., i b$.

${ }^{33} I d ., i b ., i b$.
} 
a massa da população não podia recorrer. Talvez fosse boa a solução em termos pessoais, mas o que fazer com o povo? Meses depois, Quatro-Olhos recebia carta dela, falando de neve em aldeota alemã. Recebeu essa carta na agência de filmes, enquanto cuidava de arranjar flores para o anúncio de desodorante. 'O Brasil me fez perder duas mulheres', pensou. E logo descobriu o que tinha de fazer. Escrever outra vez o livro. ${ }^{34}$

Além de uma solução para sua situação com as mulheres, a reescrita responde à condição do povo brasileiro. Então, reescrever o livro é também recuperar uma utopia para o povo brasileiro. Precisamos agora ver a qual utopia corresponde o projeto político de Quatro-Olhos - já que colocava em xeque outros projetos políticos, seja pela ridicularização, seja pela compreensão da suposta condição de massa de manobra.

Como já dissemos, segundo o protagonista de Quatro-Olhos em "Dentro", o assunto principal do livro perdido era a rosa, símbolo da utopia. Mas essa utopia precisa ser nuançada. No início do quinto fragmento, lemos: "Na verdade, porém, embora meu trabalho tivesse alcançado proporções festivas, o fato é que sempre vivi separado do povo, como em redoma morta, imune a seu suor e sua umbanda, seus terrores e suas criações" . 35 Note-se que, embora a referência à utopia, a rosa, esteja vinculada imageticamente ao campo progressista das lutas sociais, quando o protagonista fala dos efeitos políticos de seu trabalho deixa ver uma posição distanciada do povo, de modo que seu projeto era um projeto estético, que ele queria magistral, mas sem vínculo com as mudanças sociais que se desenhavam no horizonte quando escrevera o livro perdido. Em outros momentos, quando recorda do escrito, a utopia figura como uma grande roda com pessoas de mãos dadas, cantando alegremente, sucedida por uma fila burocrática que encerra a roda feliz. Com essa imagem da utopia, a rosa deixa de ser o símbolo revolucionário e passa a ser o símbolo cristão da união, do amor, da comunhão. De todo modo, um projeto político abstrato, na medida em que ele apenas se materializa em imagens genéricas, talvez um clichê, fundado não na alteração da sociedade, mas na construção de uma grande obra de arte, ao que se soma o beletrismo das referências literárias, que mencionamos no início deste estudo.

No conjunto das utopias que o protagonista ridiculariza e, no limite, utopias a que opõe sua obra literária, além daquelas ligadas à renovação estético-política que se operava nos anos anteriores ao golpe, há uma que

${ }^{34} I d .$, ib., p. 188.

${ }^{35} I d .$, ib., p. 49. 
tem papel central no romance: a luta da esposa. No vigésimo terceiro fragmento, acompanhamos parte da narrativa conjugal:

Ela queria nada mais que transformar o mundo. Mas eu no fundo apenas verbalmente acompanhava esse projeto; fazia para mim muito mais sentido obedecer aos ritos de repartição e fora daquele horário sagrado prosseguir o livro, que nunca mostrei a minha mulher quando escrevia, dizia a ela que estava estudando. Tinha receio de que ela chamasse o livro de alienado [...].

Fomos vivendo num modesto apartamento de quarto-esala, até que terminei os estudos e surgiu o banqueiro secretário de Estado[...]. Isso me duplicou a renda e passamos a um apartamento maior. Minha mulher prosseguia nos estudos e fazia carreira universitária. Mas não era o centro da vida dela - sua razão de viver eram as reuniões de que participava dentro e fora de casa. Eu achava que os exploradores do povo nada tinham a temer daqueles coiós que apareciam em casa, no entanto me enganei; vários deles foram presos em 1964 e depois em 1968. Esses dois anos aliás vieram introduzir profundas alterações no modo de minha mulher encarar as coisas. Antes de 1964 ela era radical e não aceitava aliança com nenhum grupo burguês; depois ela se dividiu: o cérebro lhe dizia da necessidade de formar frentes para acumular forças, o coração lhe pedia ação radical. Ela cultivava relações nos dois meios, na esquerda tradicional e na esquerda radical e queria sempre estar a par de tudo. De mim afinal creio que ela gostava, pois só me deixou no último momento, embora logo tivesse percebido que eu não tinha estofo de líder revolucionário, seu ideal de homem.

[...]

Me embuía da ideia de tornar eterno, porque escrito, o perfume fanado de uma flor antiga ${ }^{36}$

Embora longa, a citação nos permite verificar a relação do projeto literário da rosa com o projeto político da esposa. A percepção da personagem de todo o processo dá testemunho de uma certa leitura convencional que se formulou da esquerda ao longo dos anos: somado a outros momentos em que a personagem principal ridiculariza a luta da esposa, há implícito certo senso comum de que a esquerda pré-golpe e nos anos iniciais, até o AI-5, vivia uma ilusão sem sustentação popular. Também destila uma compreensão do que foi a opção pela luta armada,

${ }^{36} I d .$, ib., p. 129. 
aqui chamada de "ação radical". De todo modo, o projeto abstrato do protagonista, porque remetia à comunhão do povo, à felicidade, por via de um deus ex machina, bem como à grande obra de arte como participação política, se opõe a um projeto que, tendo lá suas complicações, estava fundado na concretude da compreensão histórica do período pré-golpe. Ilusão objetiva? Talvez, mas por ser objetiva, fundada, ainda que parcialmente, na história. O fundamento da concretude do problema é reconhecido, inclusive, pelo próprio Quatro-Olhos ("me enganei"), ainda que isso não altere sua insistência em tentar refazer seu projeto do passado no presente.

Voltando ao projeto do livro perdido. Ao fim, a personagem central de Quatro-Olhos parece dar figuração a um tipo de intelectual brasileiro. Esse intelectual está caracterizado ostensivamente no romance como alguém enlouquecido: confusões entre realidade, ficção e delírio, alteração de tonalidades, saltos abruptos etc. - o que garante, em alguma medida, um grão de distanciamento ao leitor. Esse intelectual apresenta um projeto que tenta responder ao quadro nacional do presente, como atesta o final do romance; entretanto, esse projeto está fundado no momento da prérevolução brasileira. Além disso, trata-se de projeto que, embora progressista, é abstrato. O tempo da enunciação, por sua vez, é o tempo da expectativa, inserido no novo tempo brasileiro em que o futuro chegou e, com ele, a destruição das utopias do passado. A esse tempo novo, o intelectual tenta responder com um projeto abstrato e de um outro tempo histórico. Parece, então, haver no conjunto um diagnóstico sobre uma parcela da intelectualidade brasileira: a tentativa de responder ao presente, girando em falso, com um projeto do passado que talvez já não tenha seu fundamento histórico - se é que o de Quatro-Olhos, a grande obra de arte, teve algum.

Carlos Moacir Vedovato Junior é mestrando no programa de pós-graduação em Teoria Literária e Literatura Comparada da FFLCH-USP, onde realiza a pesquisa Uma leitura de Quatro-Olhos, de Renato Pompeu, orientado pela Profa. Dra ${ }^{a}$. Ivone Daré Rabello. Dedica-se aos estudos das relações entre o romance brasileiro e a ditadura militar. Tem experiência com ensino de literatura brasileira e portuguesa, bem como de produção textual, em cursos pré-vestibular. Contato: moacir.vedovato@gmail.com

Ivone Daré Rabello atua como professora sênior nas linhas de pesquisa do Departamento de Teoria Literária e Literatura Comparada da FFLCH-USP e na pós-Graduação: Formas e gêneros literários, Literatura e sociedade. Atualmente volta-se para o estudo da lírica de Carlos Drummond de Andrade e das formas culturais e sociais contemporâneas. É membro do grupo "Formas culturais e sociais contemporâneas". Contato: ivonedare@uol.com.br 